\title{
CONCEPTUALIZING INFORMATION TECHNOLOGY IN THE STUDY OF INFORMATION SYSTEMS: TRENDS AND ISSUES
}

\author{
Steve Sawyer \\ School of Information Sciences and Technology \\ Pennsylvania State University \\ University Park, $P A$ \\ U.S.A. \\ Tina T. Chen \\ Department of Psychology \\ Pennsylvania State University \\ University Park, $P A$ \\ U.S.A.
}

\begin{abstract}
In this paper,we discuss trends in the published research of the information systems (IS) community. To do this, we draw on the existing IS literature to show that the conceptualization of information and communication technologies (ICT) also shapes the conceptualizations of information, people, level of analysis, and research method. For evidence, we draw on two sources of IS literature: the research articles from the journal Information Systems Research (ISR) and the books published by the International Federation on Information Processing (IFIP) Working Group on Information Systems in Organization and Society (WG 8.2). Our analysis of the literature published in these two venues shows substantial differences in the conceptualization of all five constructs and attributes. In particular, there is great diversity across all five constructs and attributes in the ISR literature. The IFIP WG8.2 literature also displays a broad approach to conceptualizing ICT. In contrast to the work in ISR, the work in IFIP WG8.2 publications is also characterized by a small range of, and often nearly singular,
\end{abstract}

The original version of this chapter was revised: The copyright line was incorrect. This has been corrected. The Erratum to this chapter is available at DOI: 10.1007/978-0-387-35634-1_28 
approaches to information, people, level of analysis, and research method. Further, more than 55 percent of the articles provide little insight into the specifics of the ICT being discussed. Combined with the uses of social theories, intensive and theory-building approaches to research, and the focus on institutional levels of analysis, the IFIP WG8.2 literature may be difficult for other IS scholars to understand, even if it is more singular in its approaches. These findings suggest that the published IS literature may also be relatively inaccessible to scholars who work within the various subcommunities of this pluralistic scientific community. The diversity of approaches also means that the IS community, and scholars in other areas who might use IS research, would value work that theorizes the relationships among the various conceptualizations of ICT.

\section{INTRODUCTION}

In this paper, we discuss emerging trends in the published research of the information systems (IS) community. We frame this discussion using five generalized conceptualizations of information and communication technologies (ICT) (Orlikowski and Iacono 2001; Sawyer, 2000). Beyond simply reiterating Orlikowski and Iacono's call to better conceptualize what is meant by ICT in the IS literature, we pursue two objectives. First, we show that the conceptualization of ICT also shapes the conceptualization of specific elements of contemporary IS research. Second, we explore the general conceptualizations of ICT relative to the work in one subfield of IS research.

The chapters in this book focus on the discourse about the roles of IS in contemporary institutions. In this paper, we focus on the conceptualizations of ICT in the IS literature as a form of discourse within a particular (IS) scientific community. We do this to raise the level of attention on what is meant when we, as scholars, say IS and ICT. Through the analysis presented in this paper, we focus on the conceptualizations of ICT as a discourse shaping current IS research.

Through the empirical analysis presented below, we provide evidence that the discourse around IS research is structured by the interrelations among three constructs:

1. Information, by which we mean the data set into an organized context for use

2. Technology, by which we mean various forms of ICT 
3. People, by which we mean characterizations of humans, their structures and their actions

The findings from this analysis also suggest that the current scholarly discourse within the IS research community regarding conceptualizations of each often treats one (or more) of these constructs implicitly. Through the analysis presented in this paper, we take a small step to move the scholarly discourse in the IS research community toward a more explicit position about the meanings of, and relations among, information, ICT, and people.

In the next section, we conceptualize the study of IS as the integration of information, technology (ICT), and people constructs. In the third section, we present the analytic framework we use to classify the IS literature and explain how we selected and conducted the literature classifications. In the fourth section, we present and discuss the findings from the analysis of the selected IS literature. In the fifth section, we present our conclusions and speculate on their implications.

\section{INFORMATION, TECHNOLOGY, AND PEOPLE AS THE CENTRAL CONSTRUCTS IN IS RESEARCH}

Two premises underlie the work reported on here. First, that three constructs are at the center of IS research: information, technology ( ICT), and people. Second, what these constructs mean is often implicit and even underdeveloped in the current IS research. In this section, we provide initial working definitions of information, ICT, and people. We also provide some examples of how these constructs appear in the IS literature.

\subsection{Information}

Information is a central construct in IS research. The concept is central enough to be included in the title of the research stream. However, it is undertheorized: many IS papers have little or no text devoted to the construct. In contrast, theories and concepts of information are vibrant research efforts in philosophy (Floridi 2002), communications (Braman 1989), and information science (Borgmann 1999; Cornelius 2002; Losee 1997; Taylor 1982, 1986). Presently, two contemporary phenomena are helping bring concepts of information more directly into the forefront of IS research. First, there is the increasing attention being paid to practical and conceptual issues in managing knowledge in extant social organizations (Cross and Baird 2000). Second, there is an 
increasing level of interest in the roles that information play in the philosophical and conceptual foundations of IS (Callaos and Callaos 2002).

In each of these areas of scholarship about information, one part of the difficulty in developing a more explicit meaning is the ongoing debate on the differences between data, information, knowledge, and wisdom (Brown and Duguid 1999; Callaos and Callaos 2002; Cornelius 2002; Taylor 1982). The confusion is often caused by the conflations between data and information and between information and knowledge. ${ }^{1}$

In this paper, we characterize the use of information as a construct in the IS research in three ways: as object, as embedded, or naively. From an object view, information is a discrete entity: something that can be passed from sender to receiver with no loss of value, something that can be stored for later retrieval, or something that can exist and be understood on its own, thus, providing someone with a manual means that they will be able to understand the directions. A second way to conceptualize information is as embedded into a larger entity. In this way information is that which is in someone's head (tacit) (Brown and Duguid 1999; Polyani 1943), co-constructed through discussion (as the development of collective meaning; see Crowston and Kamerer 1998, Wynn and Katz 1997), or embedded into the design of organizational structures (organizational information processing; see Galbraith 1974). A third characterization of information is what we term a naive view. In the naive view, the meaning of information is never made explicit or, and perhaps more of a concern, there are multiple inferred meanings with no over-arching discussion of the conceptual issues with a pluralist approach to depicting information.

\subsection{Information and Communication Technologies}

For at least two reasons, the study of IS is also the study of ICT. First, most contemporary IS rely on ICT. While IS can be developed that have no ICT, increasingly they are ICT dependent and most contemporary work in IS has, at the core, some planned uses for various ICT (Kling and Scacchi 1982). Second, some of the growth in the use and value of IS can be attributed to the increased power of the underlying ICT. What is meant by ICT, however, varies. For this paper, we use the characterizations of ICT as developed empirically by Orlikowski and Iacono (2001) and conceptually by Sawyer (2000) to articulate five generalized approaches to representing the scholarly discourse in IS of what is meant by ICT. The five characterizations of ICT are: proof of concept, presence/absence, component, feature, and function. Orlikowski and Iacono

${ }^{1}$ A more detailed discussion of information is beyond the scope of this paper. 
went further, identifying forms (or a second level classification). We describe this two level classification of each approach in the following paragraphs.

The feature or tool view is the most common (or received) view of ICT. Here ICT is characterized to operate as it was designed to behave. In a tool view, the ICT is depicted as one or more feature. The roles of the ICT and its features are seen as primarily technical in nature and direct in their effect. For example, as Trauth and Jessup (2000) make clear, this has been the dominant view in group decision support systems (GDSS) research. There are four forms of the tool view of ICT: as a substitute for labor, as a means to improve productivity, as way to increase information processing, and as a means of improving/ maintaining social relations. These feature-based approaches to studying ICT focus on the values, effects, and impacts of particular (and identifiable) technical aspects of an ICT.

The proxy view of ICT is that some (often quantified) surrogate can capture or measure the value of ICT. For example, the work on the value of ICT to the firm by Brynjolfsson and his colleagues uses spending on IT as a proxy for ICT (Brynjolfsson 1994; Brynjolfsson and Hitt 1993, 1998). Three forms of proxy are identified in the contemporary IS literature. The first proxy form is the perception view of ICT. Here, perceptions of human cognition or attitudes become the proxy for what is meant by ICT. The diffusion proxy measures availability (or level of penetration) of ICT artifacts. The capital proxy means using some surrogate (such as spending on computers) as the definition of ICT (as we noted above). Proxy views of ICT focus on making clear the ways in which the measure highlights the value of the ICT.

The functional or ensemble view of ICT is that of a socio-technical package. This characterization of ICT is one where specific artifacts and people are interdependently connected through roles, uses of information, and actions. In the functional view, there is often an explicit attention on the ways of using a particular ICT. Such socio-technical arrangements can be called webs of computing, socio-technical IS or socio-technical systems (see Bostrom and Heinen 1978a, 1978b; Kling and Scacchi 1982; Sawyer and Eschenfelder 2002). The structural ensemble highlights the ways that relate ICT, structure, and action. Function-oriented characterizations of ICT focus on the values, effects, and impacts of the uses of a particular ICT. There are four general forms of the ensemble view. One way is to characterize the ICT as a method of construction/ implementation of a system (a development project) where the artifact plays a central role because around it are arranged the social and technical attributes of its construction. The production network ensemble focuses on the sets of arrangements to use ICT as a means toward an end. The embedded system view of the ICT ensemble highlights the social context as the milieu in which an artifact exists. 
The proof of concept view of ICT focuses on the computational power or abilities of an artifact. Proof of concept characterizations of ICT highlight the construction of a computational artifact, where that artifact instantiates an idea or theory of information processing (see Morrison and George 1995). There are two forms of computational artifacts. The algorithm form highlights the underlying concepts embodied in the computational artifact. The model form of computational ICT focuses on creation of a computable model or simulation to test a particular research question (or questions). In both forms, the focus is on providing evidence of a concept by developing a computational artifact.

The presence/absence or nominal view implies that discussions of ICT do not provide a definition or operational depiction of what is meant. In this approach, the characterization of ICT is implicit. Often the particular ICT is named, but the features, functions, model, or proxy are not defined. Nominal treatments of ICT are often developed as presence/absence rhetoric: contrasting situations that have ICT to situations that do not (or have different ICT, or more or less of the same ICT). One common variant of presence/absence research is what we call component research on ICT. In a component approach, various elements (such as different computing platforms like Macintosh and IBM PC or Windows and Linux) are contrasted as black boxes, with little or no discussion of the component's features, functions, proxy measures, or computational elements. The component form of the nominal approach can also be seen as a specialized form of proxy, although the development of a proxy measure provides a more precise definition than does the implied (set of) characteristics of a presence/absence perspective.

\subsection{People}

Conceptualizations of people are central to IS research, although the particular forms of how people are depicted vary greatly in contemporary IS literature (for example, see Lee 1999). IS research may focus on particular individual attributes of a person such as decision-making, technology acceptance, or conflict. Or IS research may conceptualize people as members of an organization depicted by span of control, number, structure, and purpose of units. Here organizational characteristics, not individual characteristics, are likely to be the way people are depicted.

For this work, we characterize the current IS literature's conceptualization of people in one of three ways. The first conceptualization of people is that of individual attributes or characteristics, which is typically a psychological perspective. There are, of course, a variety of psychological theories that can be (and have been) used in IS research. And there are some derivative approaches to theorizing people that draw on psychology (such as the technology acceptance 
model) that may not be used by psychologists. This characterization of people as a construct, however, follows the general characteristics of a philosophy of psychology (see Machamer 1992). A second characterization of people as a construct in IS research is social: as aggregations, units greater than one, and not individuals. In this view, collective attributes and behaviors are the focus and individual variance is not central. Such perspectives are often labeled social theories and they take the form in theories of social organization, institutional economics, new institutionalisms, and macro-economics more generally. Again, the issue is not their use in a reference discipline as much as it is that their underlying structure reflects the philosophy of social science (see Salmon 1992). A third characterization of people as a construct in IS research is what we will call naive. A naive view of people as a construct is not grounded in theory. The difference from the first two characterizations of people as a construct in IS research does not presuppose individual differences and/or aggregate/collective characteristics and behaviors, just the absence of a credible theoretical base.

This three-way characterization of people as a construct in IS research is quite broad. However, it provides a means to discriminate the ways in which people are depicted in the current IS research literature. Thus, a paper that depicts women as not able to understand ICT because of their gender would be seen as using the naive construct of people. The characterization of people (women) in aggregate (so is clearly advocating a social theory view) has no conceptual basis (so is naive). Likewise, a paper that uses the technology acceptance model (TAM) and depicts people as having beliefs and expectations of ICT use (building on two elements of TAM) would be using individual theory. Finally, a paper that depicts organizations as an information processing entity (such as is done by Ackoff 1996) would be seen as paper developing people as a social construct.

\section{THE ANALYTIC FRAMEWORK AND ANALYSIS OF THE IS LITERATURE}

The analytic framework used for analysis is presented in Table 1 and discussed in the following sections. The framework builds on the conceptualizations of the information, ICT, and people constructs as developed in the previous sections. Here we add to that framework two additional attributes: level of analysis and research method. We add these additional characteristics as both the level of analysis and research method help to define contemporary IS scholarship. Many IS scholars identify themselves by the level of their analysis and by the methods they use. Furthermore, existing IS research literature suggests that these two facets of scholarship are central discussion points in the discourse of our scientific community (e.g., Markus and Robey 1988). 
Table 1. The Analytic Framework and Coding Scheme

\begin{tabular}{|c|c|}
\hline Construct & Description \\
\hline \multicolumn{2}{|l|}{ Information } \\
\hline Object & Discrete, identifiable, and transmittable unit \\
\hline Embedded & Enmeshed in discourse, structure, or process \\
\hline Naive & Not developed or used in multiple ways \\
\hline \multicolumn{2}{|l|}{ Technology (ICT) } \\
\hline Feature (tool) & Used as intended, technical features with direct effects \\
\hline Function (ensemble) & $\begin{array}{l}\text { Socio-technical collection of artifacts, roles, rules, and } \\
\text { norms }\end{array}$ \\
\hline Proxy & Substitute measure \\
\hline $\begin{array}{l}\text { Proof of concept } \\
\text { (computational) }\end{array}$ & Artifact \\
\hline Presence/absence & Not defined or developed, just mentioned (or not). \\
\hline \multicolumn{2}{|l|}{ People } \\
\hline Individual & Theories of individuals (behaviors, cognition, attitude) \\
\hline Social & Theories of collective characteristics and behaviors \\
\hline Naive & No theory of people developed or defined \\
\hline \multicolumn{2}{|l|}{ Level of Analysis } \\
\hline Artifact & The computational effort \\
\hline Individual & People's perceptions, attitudes and behaviors \\
\hline Group & $\begin{array}{l}\text { Small collections of people (often teams and work } \\
\text { groups) }\end{array}$ \\
\hline Institution & $\begin{array}{l}\text { Larger social units (organizations, industries, } \\
\text { communities) }\end{array}$ \\
\hline \multicolumn{2}{|l|}{ Research Method } \\
\hline $\begin{array}{l}\text { Experimental (all } \\
\text { forms) }\end{array}$ & $\begin{array}{l}\text { Laboratory and field experiments, quasi-experimental } \\
\text { designs }\end{array}$ \\
\hline Intensive/field-based & $\begin{array}{l}\text { Case studies, ethnographies, deconstruction/text } \\
\text { analysis }\end{array}$ \\
\hline Computational & Models and programs \\
\hline Other & $\begin{array}{l}\text { Theory development, thought experiments, literature } \\
\text { review }\end{array}$ \\
\hline
\end{tabular}




\subsection{Core Constructs: Information, Technology (ICT) and People}

As discussed in the previous section and outlined in Table 1, we frame this analysis of current IS literature using five conceptualizations of ICT (features, functions, proxy measures, proof-of-concept, or presence/absence). We depict the information construct in the IS literature as an object, as embedded, or naive. We depict the people construct in the IS research literature as individual attributes, characteristics of social units, or naive.

For the purposes of the analysis in this paper, a reductionist coding scheme provides sufficient depth of evidence to illustrate trends in the characterizations of information, ICT, and people in the IS research literature. As we note in more detail below, when coding these three constructs, we allow for multiple representations of information, ICT, and people if the authors of the paper make these different representations explicit. Thus, a paper in which features of a particular ICT or IS are contrasted with its functional use would be classified as both feature and function research. However, if constructs are not defined or used in multiple ways without clarification, we only code the approach that is defined (or best represents the work in the absence of a definition). Thus, we would classify a paper in which claims are made about women's behaviors around computing using both individual differences and social arrangements as a naive people construct if the authors did not explicitly develop these concepts from contemporary theorizing.

\subsection{Level of Analysis}

We depict level of analysis as artifact, individual, group, and institution. The artifact level of analysis focuses the research attention to the development of a particular ICT (typically computational) artifact. The individual level of analysis is characterized by attention to individual differences in cognition, perceptions, attitudes, and beliefs. The group level of analysis focuses on small groups of people, often work groups or teams. In doing this, we treat groups as a special form of a social unit, even though they could be (and often are) treated as either an aggregation of individual characteristics or as a specific form of social aggregation. We use the term institutional to represent the levels of analysis encompassing social aggregations larger than the group. These aggregations can take the form of organizations, departments, communities, industries, and societies or subsets of each (such as women in organizations or virtual communities of practice found in online settings). 
In coding the level of analysis we allow for multiple levels to be used in any one study. To be classified this way, however, the text of the paper had to make clear the multiple levels and define how they were crossing levels of analysis. Thus, we would classify a paper in which the authors claim to study organizational decision making, but focus solely on individual differences of certain decision makers, as research at the individual level of analysis. Conversely, we would classify a paper in which the authors depict resource allocation issues among teams and the ways in which these allocation issues are handled at the organizational level as research being done at both group and institutional levels of analysis.

\subsection{Research Method}

For research method, we use a four-part characterization. We characterize all laboratory, field and quasi-experiments as experimental research methods. We classify case studies, fieldwork and ethnographies, deconstruction and other textual analyses, and historical analyses as intensive approaches to research. Development of artifacts such as models and algorithms are classified as computational approaches to research. And, we classify as other research approaches such as theory development, thought experiments and literature reviews. Again, the use of such broad categories masks some of the rich variety of methods used in IS. Despite the granularity, these four categorizations are sufficient to help represent trends in contemporary IS research. As we did for levels of analysis, we code for multiple forms in any one study. That way, a study using surveys and fieldwork (such as Kaplan and Duchon 1988) would be coded as both experimental and intensive.

\subsection{Selection of Literature}

To support our analysis, we use the published research literature from two sources: a premier IS journal and the collected works from working conferences of one of the IS subfields. We use the work published in Information Systems Research (ISR) to represent the IS field's work. In this way, the work in ISR stands as a proxy of the IS field. There are at least two reasons for selecting ISR as a representative publication of IS research. First, ISR is a premier journal in the IS field: rated in the top three in a recent summary of IS publication and consistently rated as a premier journal (Dalal 2002; Mylonopoulos and Theoharakis 2001). Second, the published work in ISR served as the empirical basis for Orlikowski and Iacono's (2001) categorization of ICT. 
For a representative subfield, we use the published work from the International Federation on Information Processing (IFIP) Technical Committee 8, Working Group on Information Systems in Organizations and Society (IFIP WG 8.2). There are at least three reasons for choosing this as the subfield of IS to be used for comparison to the ISR literature. First, we are members of this community and, as members, are interested in making clear the specific contributions of this vibrant area of scholarship to the IS literature (both for ourselves and for others). Second, the published work of IFIP WG 8.2 is collected into a series of edited books, making this literature both accessible and easy to locate. Third, as scholars of IS (and thus of ICT) and organization, we seek to advocate that the research trends in IFIP WG 8.2, such as the emphasis on social theory (development and use) provide particularly valuable insights for other IS scholars (Jones 2000). Certainly journal and conference submissions differ with respect to editorial focus, review process and time scale. However, this comparison focuses on constructs, not review processes, so these differences are not central to the analysis (for more on editorial peer review, see Weller 2001).

\subsection{Coding the Articles}

We coded articles from both sources published between 1990 and mid-2001 (Volume 12, Issue 2 of ISR.). We selected 1990 as the start of our coding because that is when ISR began publishing. This resulted in 166 coded articles from 12 issues of $I S R$ and 201 articles from the seven IFIP WG 8.2 books. We included all research articles and research notes from ISR and all research articles from IFIP WG8.2 (we omitted panel and section summaries). The coding scheme was developed a priori and refined through initial coding of ISR articles (see Table 1).

Initial article coding was done by the second author, then contrasted to the coding of the first author. As is typical in dual coding efforts, differences in the coding of an article were resolved through discussion. Three empirical issues hampered coding. First, the contemporary IS research is not written in a way that makes it easy to assess how information, ICT, and people are depicted. While this is to be expected, given the argument we advance that these are often implicit to IS research, it is time-consuming to draw the elements and attributes from the published material. Second, the level of analysis and research methods elements are often better presented, but not always easy to find in the papers. Third, several papers have multiple perspectives on the three constructs (and occasionally use multiple methods and levels of analysis). In the cases where there were multiple methods or levels of analysis, we coded all of them. Thus, for example, the number of occurrences of a level of analysis may exceed the number of articles. 
The resulting coded data set developed through this effort does not duplicate the work done by Orlikowski and Iacono. There are at least two other reasons beyond the obvious distinction that we coded for other elements beyond the depiction of ICT in the literature. First, we included extra ISR articles (published since Orlikowski and Iacono did their analysis). Second, they present summaries of their coding results (not details) so there are likely to be differences on the coding of specific papers. The differences among the coded ISR data sets are less important at this time than are the findings. Thus, we have not attempted to resolve differences by comparing coded data sets.

\section{FINDINGS}

The findings from our analysis of the two sets of IS literature are presented here. Through this analysis, we pursue responses to questions about the relationships among the five constructs. In this way, we can respond to questions such as: What is the dominant characterization of information? Do characterizations of people vary by characterizations of ICT? Are there relationships between level of analysis and characterizations of people?

In Table 2 we summarize the findings of the ISR literature. ${ }^{2}$ In addition, characterizing the relationships among findings and depictions of ICT is likely to help provide structure for the ongoing discourse around integrating the findings from one characterization (of, say ICT) with another (e.g., Baskerville and Myers 2002; Keen 1980). That is, a scheme like what we envision (and do not now have) can help us answer questions such as how are feature-based findings of ICT use influencing the work being done where ICT are characterized as functions/ensembles? A summary of the findings of the IFIP WG 8.2 literature is presented in Table 3 . These analyses are organized by the characterizations of ICT and the related patterns depicting information, people, level of analysis, and research methods. We present summary-level analysis of the IS literature in lieu of detailed compilations to conserve space. In this summary, we represent a finding as a trend if one of the following criteria are met:

\footnotetext{
${ }^{2} \mathrm{We}$ do not code the contributions relative to the various characterizations of ICT. However, we recognize the importance of developing such a coding scheme for two reasons. First, such a scheme will help us better understand the form of the findings relative to ICT and IS. By form of contribution, we mean here the ways in which the findings are characterized. That is, some of the form issues might include: (1) Are particular types of findings tied to specific features of an ICT or IS? (2) Do particular findings reflect particular theories of people, information, or ICT? (3) Are findings typically represented in the ways that the constructs are developed?
} 
Table 2. Information Systems Research Literature Summary

\begin{tabular}{|l|c|c|c|c|c|}
\hline $\begin{array}{c}\text { Form of } \\
\text { ICT }\end{array}$ & Feature & Proxy & Function & $\begin{array}{c}\text { Proof of } \\
\text { Concept }\end{array}$ & $\begin{array}{c}\text { Presence/ } \\
\text { Absence }\end{array}$ \\
\hline $\mathrm{N}=166$ & 32 & 47 & 37 & 37 & 13 \\
\hline Inform. & Object & $(?)$ & Embedded & Object & $(?)$ \\
\hline People & Individual & Naive & Social & Naive & $(?)$ \\
\hline $\begin{array}{l}\text { Level of } \\
\text { Analysis }\end{array}$ & $\begin{array}{c}\text { Individual } \\
\text { Group }\end{array}$ & $\begin{array}{c}\text { Individual } \\
\text { Institution }\end{array}$ & Group & $\begin{array}{c}\text { Artifact } \\
\text { Institutional }\end{array}$ & $(?)$ \\
\hline $\begin{array}{l}\text { Research } \\
\text { Method }\end{array}$ & Experimental & $\begin{array}{c}\text { Experimental } \\
\text { Intensive }\end{array}$ & Intensive & Model & $(?)$ \\
\hline
\end{tabular}

Table 3. IFIP WG 8.2 Literature Summary

\begin{tabular}{|c|c|c|c|c|c|}
\hline $\begin{array}{l}\text { Form of } \\
\text { ICT }\end{array}$ & Feature & Proxy & Function & $\begin{array}{l}\text { Proof of } \\
\text { Concept }\end{array}$ & $\begin{array}{c}\text { Presence/ } \\
\text { Absence }\end{array}$ \\
\hline$N=201$ & 32 & 18 & 59 & 2 & 90 \\
\hline Inform. & Naive & Naive & $\begin{array}{l}\text { Embedded } \\
\text { Naive }\end{array}$ & Object & Niave \\
\hline People & $\begin{array}{l}\text { Individual } \\
\text { Social }\end{array}$ & Individual & $\begin{array}{l}\text { Individual } \\
\text { Social }\end{array}$ & Naive & Individual \\
\hline $\begin{array}{l}\text { Level of } \\
\text { Analysis }\end{array}$ & Institutional & Institutional & Institutional & $\begin{array}{l}\text { Artifact } \\
\text { Group }\end{array}$ & Institutiona \\
\hline $\begin{array}{l}\text { Research } \\
\text { Method }\end{array}$ & $\begin{array}{l}\text { Theory } \\
\text { Intensive }\end{array}$ & Intensive & $\begin{array}{l}\text { Theory } \\
\text { Intensive }\end{array}$ & Model & $\begin{array}{l}\text { Theory } \\
\text { Intensive }\end{array}$ \\
\hline
\end{tabular}

1. More than 50 percent of the articles are coded in the same way relative to the construct.

2. No one perspective of a construct is dominant, but two of the codes account for at least 75 percent of the representations in the collection of IS research articles. 
3. One coding category is at least 40 percent of the total number of coded articles, and no other form of coding is more than 20 percent of the total number of coded articles.

\subsection{Trends in the $I S R$ Literature}

Our analysis of the ISR literature for trends among the five constructs and attributes reveals four findings. First, for both proxy and presence/absence views of ICT (36 percent of papers), there are no clear patterns of relationships among the five constructs. ${ }^{3}$ Moreover, these papers provide little insight into ICT since the characterizations are either implicit or based on surrogate measures. Second, there is no dominant characterization of the information or people constructs in the ISR literature. Third, there are no dominant perspectives relative to level of analysis or research method in the ISR literature. Fourth, there are discernable patterns of relationships (trends) in the ISR literature when ICT is conceptualized as features, functions, and proof of concept. In the rest of this subsection, we discuss the absence of patterns in the $I S R$ literature and outline the trends for feature, function, and proof of concept approaches to IS research as published in ISR.

No Dominant Pattern: While there are patterns within a particular depiction of ICT, there are no clear patterns across the published ISR literature for information, people, ICT, level of analysis, or research method. It seems that IS research, at least through the material published in $I S R$, is quite diverse across the constructs and attributes of research we have used to structure the coding and analysis. Jane Webster, writing in Lee (2001, p. xii), makes the point that IS literature (albeit, the literature published in MIS Quarterly, another leading IS journal), has come "a long way in terms of conducting empirical research." Drawing on Thomas Kuhn's (1970) concepts of science, she makes the case that IS research has come to some sort of paradigmatic maturity. This paradigm seems to embrace, at least by the measure of what is published in ISR, a diversity of perspectives on ICT and the other four constructs and attributes of IS research.

ICT as Features: Articles that depict ICT as collections of features account for 19 percent of ISR articles. In these papers, the dominant characterization of information is as an object. People are characterized as individuals and the level of analysis is focused on the individual. Feature-based ICT research is most

\footnotetext{
${ }^{3}$ As an aside, one reason that there is no clear pattern in the proxy papers is that it combines both macro- and micro-economic views. However, a post hoc assessment of these articles does not support this speculation.
} 
often conducted as a form of experiment. While we have no explicit way to represent this, it seems that findings from IS literature that depict ICT as a set of features are commonly presented in factor model forms and ICT use is depicted as a direct effect.

ICT as Function: Articles that depict ICT as functions or ensembles account for 22 percent of ISR articles. In these papers information is depicted as embedded in some discourse or larger context. People are treated as social entities (often characterized as behaviors of institutions and other organizations). The dominant research approach is a form of field study or intensive method. When ICT are characterized functionally, the research is typically structured as cross-level analyses. The cross-level analysis relates individuals to both groups and to larger institutional settings. Findings of this form of IS scholarship seem to be represented as process models or models of social structures. The ICT is often depicted in terms of the broad functionality that it provides. The views on IS functionality are almost never connected to work being done by scholars pursuing feature-based or proof-of-concept approaches to ICT.

ICT as Proof of Concept: Characterizations of ICT as a proof of concept account for 22 percent of $I S R$ articles. In these papers, information is always treated as an object and the artifact is the level of analysis. A large number of the papers in which ICT is characterized as a proof of concept also model or depict an institutional setting, making this a second level of analysis. The research method is always computational and the predominant view of people is naive. Common elements of the contributions of this type of IS research often highlight the current limitations of the computational artifact, point to the successes, and always state that the line of work is worth continuing. A second common contribution seems to be claims made about the utility of the model for people (such as decision makers) or value to people for using the developed ICT. However, there is rarely a test (or evaluation) of such claims. And, claims about the effects of the ICT or models are rarely integrated into the current literature of anything but that dealing directly with the ICT.

\subsection{Trends in the IFIP WG 8.2 Literature}

Our analysis of the IFIP WG 8.2 literature for trends among the five constructs and attributes reveals seven findings. First, 55 percent (108 of 201) of the papers represent ICT as either a proxy or as presence/absence. This means that more than one-half of the published IFIP WG8.2 research literature provides little specific insight into ICT. Second, the dominant characterization of information in the IFIP WG8.2 literature is naive. Third conceptualizations of people in the IFIP WG8.2 literature are well-developed and tied to both individual and social characterizations. Fourth, the primary level of analysis in the IFIP WG8.2 literature is institutional. Fifth, the primary research methods 
in the IFIP WG8.2 literature are intensive and often theory-building. Sixth, there is almost no proof-of concept research published in the IFIP WG8.2 literature. Finally, there are discernable patterns of relationships (trends) in the IFIP WG8.2 literature when ICT is conceptualized as features, proxy, functions, and as presence/absence. In the rest of this subsection, we discuss each of the findings and outline the feature, function, proxy, and presence/absence approaches to IS research as published in the IFIP WG8.2 literature.

Characterizing ICT, Information, and People. With 55 percent of the papers published in IFIP WG8.2 contributing little to our understanding of ICT, it would seem that this community's discourse is focused on other issues. Since the dominant characterization of information in the IFIP WG8.2 literature is naive, this suggests that the scholarly discourse in the IFIP WG8.2 literature is conceptualizing people. Nearly 97 percent (192 of 201) of the published papers in the IFIP WG8.2 literature provide well-developed depictions of people.

The Institution as Level of Analysis. Analysis indicated that the IFIP WG8.2 literature is primarily oriented toward the institution as the level of analysis, with 141 of the 201 (70 percent) papers focused on social units larger than groups (another 10 articles focused on the group level of analysis). Often the analysis reported on in the papers spans several institutional levels such as organization to industry or community to society.

Theory Building and Intensive Approaches to Research. The primary research methods in the IFIP WG8.2 literature are intensive and often theorybuilding. These two approaches account for 85 percent of the published work (169 of 201). Theory building research was originally coded as other. The large number of IFIP WG8.2 articles that focused on this led us to specifically identify this approach for reporting here (as 91 of 201 articles (46 percent) focus on theory development). Often the two were done together: intensive approaches served as the basis for theory generation.

ICT as Feature: Articles that depict ICT as collections of features account for 16 percent of IFIP WG8.2 articles. In these papers, the dominant characterization of information is naive. People are characterized as both individuals and as social units and the level of analysis is institutional. Feature-based ICT research is most often conducted as either a theory-building or intensive research effort. While we have no explicit way to represent this, it seems that findings from IS literature that depicts ICT as a set of features are commonly presented in some form of a research model and ICT use is depicted as a moderator or mediator.

ICT as Proxy: Articles that use surrogate measures account for 9 percent of IFIP WG8.2 articles. In these papers, information is depicted naively. People are depicted as individuals. The dominant research approach is some form of intensive method and the surrogate is often some IS requirements. Findings often focus on the development and uses of IS requirements. 
ICT as Function: Articles that depict ICT as functions or ensembles account for 30 percent of IFIP WG8.2 articles. In these papers, information is depicted naively. People are treated as both individual and social entities (often characterized as behaviors of institutions and other organizations). The dominant research approach is some form of intensive method, often focused on theory building. When ICT are characterized functionally, the research is typically structured as a cross-level analysis, but at varying aggregate (thus institutional) levels. The ICT is often depicted in terms of broad functionality that it provides and as some socio-technical arrangement.

ICT as Presence/Absence: Articles that provide little or no details on the ICT account for 45 percent of IFIP WG8.2 articles. In these papers, information is depicted naively. People are treated as both individual and social entities (often characterized as behaviors of institutions and other organizations). The dominant research approach is some form of intensive method, often focused on theory building. When ICT are characterized functionally, the research is typically structured as a cross-level analysis, but at varying aggregate (thus institutional) levels. The ICT is often depicted in terms of broad functionality that it provides and as some socio-technical arrangement.

\subsection{Comparing the Characterizations of the ISR and IFIPWG8.2 Literature}

Here we contrast the published IS work from ISR and IFIP WG8.2. These contrasts are not developed through tests of distributions or variance. Rather, we comment on the differences in the trends for each of the five constructs and attributes used in our coding. This analysis encompasses 367 articles published between 1990 and 2001. Across the two sets of IS literature, there are different characterizations of ICT. The ISR literature contains more proof of concept approaches (19 percent of total), although these are nearly non-existent in the IFIP WG8.2 literature. Proxy approaches to ICT are 28 percent (47 of 166) of the ISR papers, though they represent only 9 percent of the work in IFIP WG8.2. However, presence/absence studies make up 45 percent of the IFIP WG8.2 literature compared to 8 percent of the ISR literature.

There are different characterizations of information in the two sets of literature. In the IFIP WG8.2 literature, 171 of 201 papers ( 85 percent) develop naive characterizations of information. The ISR literature has relatively large numbers of each approach to characterizing information. The two sets of literature also have different characterizations of people. In the ISR literature, there is a diversity of conceptualizations of people, with nearly 50 percent ( 82 of 166) of the papers presenting a naive depiction of people. In the IFIP WG8.2 litera- 
ture, people are theorized with great clarity and care. Only 9 papers of the 201 in the IFIP WG8.2 literature present naive depictions of the people construct.

There are differences in the levels of analysis between the two sets of IS literature. Again, the $I S R$ literature has a wide range of approaches to depicting levels of analysis. The IFIP WG8.2 work is almost exclusively focused on institutional levels of analysis and is essentially not focused on the ICT as artifact. The IFIP WG8.2 literature presents a nearly exclusive focus on theory building and intensive methods. In the $I S R$ literature, there is a broad selection of experimental, model building, and intensive approaches to be found.

\section{CONCLUSIONS AND IMPLICATIONS}

In this analysis of IS research, we focused on the differences in conceptualizations of ICT, information, people, level of analysis, and research method. Both the analysis and framework can help research consumers better appreciate the strengths and limitations a particular form of studying an IS implies. A more explicit recognition of these five characterizations of ICT can also help researchers to better position their work and maximize its value by being more explicit about the ways in which their works contributes to understanding IS. These findings also help to make clear that the research trends of a specific subfield's literature may be more coherent (or at least more similar) than that of the larger field of IS research. While this seems trivial when said, it has important ramifications for both understanding the research discourse of the larger field and for the value of IS work to the discourse in other related scientific fields.

\subsection{IS Research as Discourse: Plurality or Babble?}

This analysis showcases the diversity of the material published in ISR. It may be that the ISR literature reflects the differing perspectives of the subfields that make up IS. In contrast, the IFIP WG8.2 research seems quite focused. The IFIP WG8.2 literature commonly uses social theories, intensive and theorybuilding approaches toward doing research, and attention to institutional levels of analysis. However, these approaches are rarely seen in the ISR literature. As an aside, this also suggests that the IFIP WG8.2 literature may be difficult for other IS scholars to understand, even if it is more singular in its approaches.

While diversity in the literatures of ISR and IFIP WG8.2 suggests a vibrant IS research discourse, it is not clear that a unified picture emerges. Do the different subfields interact, or do they just cohabitate in $I S R$, moving in some socially-developed rhythm of parallel efforts: each subfield valuing its work in 
ISR while ignoring the work arising from other subfields that is also published in the same journal? If the IFIP WG8.2 community is representative of the distinctness of the other IS research subcommunities, this vibrancy in IS research may seem by others to be, instead, incoherence: a nondirectional collection of seemingly similar work. That is, the differences in conceptualizations of ICT, information, people, level of analysis, and research methods may differ among the subfields of IS to such a degree that scholars in one IS subfield cannot make sense of the literature published in another IS subfield.

The plurality of views on ICT, information, people, research method, and level of analysis reflects both the growth of, and growing acceptance for, various perspectives in IS scholarship. Adherents to Kuhn's (1970) view of science might see this as the natural state of a preparidigmatic field. Feyerabend (1975) takes a more radical view of science and the values of a single dominant paradigm than does Kuhn. He suggests that a scientific community should ensure that there is no dominant ideology. Feyerabend's view may even be interpreted as embracing any view that seems to stand against the development of any preferred approach to the conduct of science. He would be pleased with the current state of the IS research discourse. The contemporary IS literature seems to lie between the singular dominant paradigm espoused by Kuhn and the anarchy espoused by Feyerabend. The bigger question, unresolved here, is the end point to which IS scholarship is heading

\subsection{IS Research Contributions to Other Scientific Communities: Signal or Noise?}

Can scholars outside of the IS research discourse community take from (or make sense of) our literature? Do they see common findings emerging or does the plurality of approaches to characterizing ICT and the other four constructs and attributes make the IS literature seem incoherent? Scholars within the IS research community suggest that our research should be a growing reference source for other scientific communities (Baskerville and Myers 2002). However, contemporary literature suggests that IS research is not being used by closely allied fields such as information science (see Ellis et al. 1999). Certainly, and in the face of Webster's optimism (Lee 2001), the IS community has not achieved the level of visibility for its work than has the much smaller (and equally vibrant) science, technology, and society (STS) scientific community (see Dutton 1999; Mackenzie and Wacjman 1999).

The coherence of IS research may be suffering because the value of our pluralistic perspectives is not being framed with any coherent structure. While the literature of any one subfield may be coherent, the collected findings of these 
fields (as showcased in leading journals like $I S R$ ) may mask this coherence. As Orlikowski and Iacono (2001) point out, the various characterizations of ICT suggest that as a field we have not been able to adequately conceptualize the central construct of our community's research discourse. And, with more than 36 percent (or 60 of 166 published articles) of the ISR articles providing no conceptualization of the ICT or IS that they purport to study, the evidence seems compelling that the IS research noise is greater than the IS research signal.

\subsection{Opportunities for IFIP WG 8.2 and Other IS Scholars: Clarifying the Discourse}

We see at least three opportunities for IS scholars in general and IFIP WG8.2 scholars in particular to reduce the potential for making our scholarship more valuable without sacrificing the pluralistic nature of our discourses. First, we should focus on developing the technical aspects of a social perspective of IS. The overwhelming use of institutional perspectives on ICT by IFIP WG8.2 scholars suggests that we are well-positioned to push forward on defining the technical characteristics of socio-technical systems (e.g., Kling and Lamb 2000). The Kling and Lamb work is indicative of such efforts, and the opportunity here is to move forward on developing technical characterizations of social perspectives, not to advocate a particular approach.

A second opportunity for IS scholars is to begin theorizing on the relations among the various characterizations of ICT. For example, in what ways can a feature-based characterization of an ICT be mapped to a function-based characterization of that same ICT? We know of no work at this time that addresses the relations among the various characterizations of ICT. Such an effort may lead to the larger theory of ICT that Orlikowski and Iacono call for in their article. This larger theory of ICT may also be one of the most valuable contributions to science by the IS research community. Currently much of the conceptualizations of ICT are arising from the STS research community, so we would be wise to study their literature in more depth.

A third opportunity for IS scholars is to focus on cross-level-of-analysis efforts. It may be that different levels of analysis demand different characterizations of ICT. Certainly the simple summaries presented in this paper suggest this is so. Markus and Robey (1988) called for this nearly 15 years ago and there has been very little empirical work done across levels despite the general agreement that this is needed. One reason may be, as Dutton (1999) suggests, that most social science researchers tend to initiate small research efforts. It seems important that the IS research community more aggressively seek funding to conduct large-scale, multi-level research on the roles of IS and ICT. 
One point that we make in this paper is that the discourse on what we mean by ICT has been both muted yet central to our research community. After more than 25 years of sustained research, can we now say more about ICT as a construct? What can we tell other scholars of our research, our characterizations of people and information, our research approaches, the levels we focus on for analysis and theorizing? The plurality of approaches to these constructs and attributes suggests that the IS research community is grappling with the correct phenomena. We encourage a more focused attention to developing some common links among these subcommunity discourses. In doing this, we advocate connections among perspectives, not domination by one perspective. We eschew Kuhn's view of paradigm for Feyerabend's more difficult (but insightful) perspective that multiple ideologies are the sign of intellectual health. Our discourse will be more productive for us and more useful for others if we can connect the pluralistic approaches to characterizing ICT and our research into a coherent framework for scholars in other fields (and professionals in the IS field!).

\section{REFERENCES}

Ackoff, R. “On Learning and Systems That Facilitate It," Quality of Management Journal (5:2), 1996, pp. 27-35.

Baskerville, R., and Myers, M. "Information Systems as a Reference Discipline," MIS Quarterly (26:1), 2002, pp. 1-14.

Borgmann, A. Holding on to Reality: The Nature of Information at the turn of the Millennium. Chicago: University of Chicago Press, 1999.

Bostrom, R., and Heinen, S. "MIS Problems and Failures: A Socio-Technical Perspective, Part 1: The Causes," MIS Quarterly (1:3), 1978, pp. 17-32.

Bostrom, R., and Heinen, S. "MIS Problems and Failures: A Socio-Technical Perspective, Part 2: The Application of Socio-Technical Theory," MIS Quarterly (1:4), 1978, pp. 11-27.

Braman, S. "Defining Information," Telecommunications Policy (13), 1989, pp. 233-242.

Brown, J., and Duguid, P. "Organizational Learning and Communities of Practice," Organization Science (2:1), 1991, pp. 40-57.

Brynjolfsson, E. "Information Assets, Technology, and Organizations," Management Science (40:12), 1994, pp. 1643-1662.

Brynjolfsson, E., and Hitt, L. "Beyond the Productivity Paradox," Communications of the ACM (41:8), 1998, pp. 49-55.

Brynjolfsson, E. , and L. Hitt. "Is Information Spending Productive? New Evidence and New Results," MIT Center for Coordination Science (April 26, 1993 Draft, 1993, pp.

Callaos, N., and Callaos, B. "Toward a Systematic Notion of Information: Practical Consequences," Informing Science (5:1), 2002 (available online at www.inform.nu).

Cornelius, I. "Theorizing Information for Information Science," in B. Cronin (ed.), Annual Review of Information Science and Technology. Medford, NJ: Information Today, Inc., 2002, pp. 393-425.

Cross, N., and Baird, L. "Technology Is Not Enough: Improving Performance by Building Organizational Memory," IEEE Engineering Management Review, Spring 2000, pp. 69-78. 
Crowston, K., and Kamerer, E. “Collective Mind in Software Requirements Development," IBM Systems Journal (36:1), 1998, pp. 1-24.

Dalal, N. "IS Journals," an ISWorld Website (available http://catt.bus.okstate.edu/isworld/ journal2.htm, last accessed 28 February 2002).

Dutton, W. "The Web of Technology and People: Challenges for Economic and Social Research," Prometheus (17:1), 1999, pp. 5-20.

Ellis, D., Allen, D., and Wilson, T. "Information Science and Information Systems: Conjunct Subjects, Disjunct Disciplines," Journal of the American Society of Information Science (50:12), 1999, pp. 1095-1107.

Floridi, L. "What is the Philosophy of Information?," Metaphilosophy (33:1\&2), 2002, pp. 123145.

Feyerabend, P. "How to Defend Humanity Against Science," Radical Philosophy (11), 1975, pp. 3-8.

Galbraith, J. "Organization Design: An Information Processing View," Interfaces (4:3), 1974, pp. 28-36.

Jones, M. "The Moving Finger: The Use of Social Theory in WG 8.2 Conference Papers, 19751999," in R. Baskerville, J. Stage, and J. I. DeGross (eds.), The Social and Organizational Perspective on Information Technology. Boston: Kluwer, 2000, pp. 15-31.

Kaplan, B., and Duchon, D. "Combining Qualitative and Quantitative Methods in Information Systems Research: A Case Study,” MIS Quarterly (12:4), 1988, pp. 571-586.

Keen, P. "MIS Research: Reference Disciplines and Cumulative Traditions," in E. McLean (ed.), Proceedings of the First International Conference on Information Systems, Philadelphia, PA, 1980.

Kling, R. , and Lamb, R. "IT and Organizational Change in Digital Economies: A SocioTechnical Approach," in B. Kahin and E. Brynjolfsson (eds.), Understanding the Digital Economy -- Data, Tools and Research. Cambridge, MA: MIT Press, 2000.

Kling, R., and Scacchi, W. "The Web of Computing: Computer Technology as Social Organization," Advances in Computers (21), 1982, pp. 1-90.

Kuhn, T. The Theory of Scientific Revolution. Cambridge, MA: Harvard University Press, 1970.

Lee, A. "Inaugural Editor's Comments," MIS Quarterly (23:1), 1999, pp. i-ix.

Lee, A. "Research in Information Systems: What We Haven't Learned," MIS Quarterly (25:4), 2001, pp. i-xiv.

Losee, R. "A Discipline-Independent Definition of Information," Journal of the American Society of Information Science (48:3), 1997, pp. 254-269.

Machamer, P. "Philosophy of Psychology," in M. Salmon, J. Earman, C. Glymour, J. Lennox, P. Machamer, J. McGuire, J. Norton, W. Salmon and K. Schaffner (eds.), Introduction to the Philosophy of Science. Indianapolis, IN: Hackett Publishing Company, 1975, pp. 346-363.

Mackenzie, D., and Wajcman, J. The Social Shaping of Technology. Philadelphia: Open University Press, 1999

Markus, M. L., and Robey, D. "Information Technology and Organizational Change: Conceptions of Causality in Theory and Research," Management Science (34:5), 1988, pp. 583-598.

Morrison, J., and George, J. "Exploring the Software Engineering Component in MIS Research," Communications of the ACM (38:7), 1995, pp. 80-91.

Mylonopoulos, N., and Theoharakis, V. "Global Perceptions of IS Journals: Where Is the Best Research Being Published?," Communications of the ACM (44:9), 2001, pp. 29-33.

Orlikowski, W., and Iacono, S. "Desperately Seeking the 'IT' in IT Research: A Call to Theorizing the IT Artifact," Information Systems Research (12:2), 2001, pp. 121-124.

Polanyi, K. The Great Transformation. Boston: Beacon Hill Press, 1943.

Sawyer, S. "The Five Ways to Study Computing," School of Information, University of Washington, Seattle, WA (The ISI/Samuel Lazerow Lecture), December 5, 2000. 
Sawyer, S., and Eschenfelder, L. "Social Informatics: Perspectives, Examples, and Trends," in R. Cronin (ed.), Annual Review of Information Science and Technology. Medford, NJ: Information Today Inc./ASIST, 2002, pp. 427-465.

Salmon, M. "Philosophy of the Social Sciences," in M. Salmon, J. Earman, C. Glymour, J. Lennox, P. Machamer, J. McGuire, J. Norton, W. Salmon and K. Schaffner (eds.), Introduction to the Philosophy of Science. Indianapolis, IN: Hackett Publishing Company, 1992.

Taylor, R. "The Value-Added Model," in The Value-Added Processes in Information Systems. Norwood, NJ: Ablex Publishing Corporation, 1986, pp. 48-70.

Taylor, R. "Value-Added Processes in the Information Life Cycle," Journal of the American Society for Information Science (30:10), 1982, pp. 341-346.

Trauth, E., and Jessup, L. "Understanding Computer-Mediated Discussions: Positivist and Interpretive Analyses of Group Support System Use," MIS Quarterly (24:1), 2000, pp. 123156.

Weller, A. Editorial Peer Review: Its Stengths and Weaknesses. Medford, NJ: Information Today, 2001.

Wynn, E., and Katz, J. "Hyperbole Over Cyberspace: Self-Presentation and Social Boundaries in Internet Home Pages and Discourse," The Information Society (13:4), 1997, pp. 297-329.

\section{About the Authors}

Steve Sawyer is an associate professor at the Pennsylvania State University's School of Information Sciences and Technology with affiliate appointments in Management Science and Information Systems, Labor Studies and Industrial Relations, and the Science, Technology and Society program. He conducts social informatics research and his current work encompasses the social processes of software development, systems implementation and related organizational changes. His work has appeared in several IFIP WG8.2 comferences and a range of publications such as ACM Computer Personnel, Annual Review of Information Science and Technology, Communications of the ACM, European Journal of Information Systems, IBM Systems Journal, The Information Society, Information Systems Journal, and Information Technology \& People. Steve can be reached by e-mail at sawyer@ist.psu.edu.

Tina T. Chen is a doctoral candidate at the Pennsylvania State University's College of Liberal Arts Psychology Department, specializing in Industrial and Organizational Psychology. Her areas of research interest include selection and performance appraisal with emphasis in gender and racial issues and assessing changes in performance over time. Tina can be reached by e-mail at ttc116@psu.edu. 